\title{
Changing Gender Roles: In Context of Female School Teachers of Ranchi
}

\author{
Mrs. Omi Singh \\ Ph.D. Research Scholar, Dept. of Sociology, \\ Ranchi University, Ranchi, Jharkhand \\ Email:misingh650@gmail.com \\ Dr. Vinita Singh \\ Associate Professor \& Head, Dept. of Sociology, \\ Ranchi Women's College, Ranchi, Jharkhand
}

\begin{abstract}
Considering the gender roles as a crucial aspect of the culture that shapes our daily life and recognizing the research gap on this topic in the context of sustainable education, the paper describes the qualitative study on changing the gender roles of female teachers.

Women are the building blocks of the society especially the teachers. It is very difficult for women to work throughout the day by managing the work schedules as well as the family when small kids are around. The organizations always demand for more and more performance. The women employees find it hard to meet the needs and playing different gender roles either it is traditional or non-traditional gender roles.

This study made an attempt to find the change in gender roles among women teaching professionals in a Ranchi school. The study also throws light on the factors which could improve the worklife balance. This study includes exploratory research on the concerned areas relating to the professional employment of women and their impact.

Family and organization need to understand the multiplicity of gender roles and the existence of work-life conflict and take necessary measures to overcome the issue. Hence it will enhance the efficiency of teachers.
\end{abstract}

Keywords: Gender, Gender roles, Family-friendly policies, Stress, Workload, Work-life balance
Reference to this paper should be made as follows:

Received: 28.07.2020

Approved: 26.09.2020

Mrs. Omi Singh

Dr. Vinita Singh

Changing Gender Roles:

In Context of Female

School Teachers of

Ranchi

Article No. 23

RJPSS Sept. 2020

Vol. XLV No. 2

pp. 201-207

Online available at:

https://anubooks.com/rjpss-

2020-vol-xlv-no-2/

https://doi.org/10.31995/

rjpss.2020.v45i01.023 
Changing Gender Roles: In Context of Female School Teachers of Ranchi

Mrs. Omi Singh, Dr. Vinita Singh

\section{Introduction:}

In the history of human development, women have been as vital as men have been. In fact, a higher status for women vis-à-vis employment and work performed by them in a society is a significant indicator of a nation's overall progress. Undoubtedly, without the active participation of women in national activities, the social, economic, or political progress of a country will deteriorate and become stagnant. But ironically and tragically, women employees in general, are not taken very seriously by their superiors, colleagues, or society at large. Having a career poses challenges for women due to their family responsibilities. Traditionally Indian women had been homemakers but in the recent decades, proper education and better awareness, in addition to the ever-increasing cost of living have made them to go out and choose careers. Men are no more being the breadwinners, but females are contributing too in the household income. With the changing role of women in the Indian society, they are not working to be independent, but the economic demand has enforce them to come up in every sector.

Teaching is a profession that requires lots of patience and empathy. Females are considered to be much more empathetic and caring. School is the place where females can easily enter into a job and feel friendly. This profession also requires them to remain updated as they have to enrich the new upcoming generation. Today the schools are growing drastically and the competition is getting very tougher. This is continuously pressuring the teachers to perform better and give excellent results. However, with the multitude of roles at work and family responsibilities, women's workforce is challenged to play different gender roles.

\section{Defining Gender}

Gender refers to the socially constructed characteristics of women and men - such as norms, roles, and relationships of and between groups of women and men. It varies from society to society and can be changed. While most people are born either male or female, they are taught appropriate norms and behaviors - including how they should interact with others of the same or opposite sex within households, communities, and workplaces.

When individuals or groups do not "fit" established gender norms they often face stigma, discriminatory practices, or social exclusion - all of which adversely affect health.

\section{A working definition of Gender:}

According to the Oxford Dictionary, the definition of gender in English is

"The state of being male or female (typically used with reference to social and 
RJPSS Sept. 2020 Vol. XLV No.2, ISSN: (P)0258-1701 (e)2454-3403 Impact Factor: 7.717

https://doi.org/10.31995/rjpss.2020.v45i01.023

cultural differences rather than biological ones. This is also called traditional concepts of gender."(1)

\section{Sex versus Gender}

In order to be able to incorporate a gender perspective into changing gender roles, it is critical to understand the meaning of gender as opposed to sex.

Sex refers to the biological and physiological characteristics that define men and women (WHO). At the same time, it may not always be possible to define sex along the dichotomous lines of male-female only, as is made evident by intersexed individuals. (2)

Gender refers to the socially constructed roles, behaviors, activities, and attributes that a given society considers appropriate for men and women (WHO). While sex and its associated biological functions are programmed genetically, gender roles and power relations and the power relations they reflect are a social construct - they vary across cultures and through time, and thus are amenable to change. (3)

\section{Gender Role}

This is the set of roles, activities, expectations, and behaviors assigned to females and males by society. Our culture recognizes two basic gender roles: Masculine and feminine. People who step out of their socially assigned gender roles are sometimes referred to as transgender.

Sexologist John Money coined the term gender role in 1955. The term gender role is defined as the actions or responses that may reveal their status as a boy, man, girl, or woman, respectively. (4)

- Gender roles are sets of societal norms dictating what types of behaviors are generally considered acceptable, appropriate, or desirable for a person based on their actual or perceived sex.

- The World Health Organization (WHO)defines gender roles as "socially constructed roles, behaviors, activities, and attributes that a given society considers appropriate for men and women." (5)

\section{Female School Teachers in India}

School is the second home for the kids where they are educated, instructed, and make to learn. Teachers are the future builders of our country; they are the providers of knowledge and wisdom. They are the basic source of education for most of the people of the country and they are the ones who build the future of the nation.

As per the United Nations, Educational, Scientific, and Cultural Organization (UNESCO) Institute for Statistics (2013) revealed that 45\% of teachers in Primary 
Changing Gender Roles: In Context of Female School Teachers of Ranchi

Mrs. Omi Singh, Dr. Vinita Singh

education of India are female. As a result, they are facing high work stress and playing different gender rolesto balance work-life. (6)

In India, teachers form the third-largest workforce among white-collared employees. Of the country's 64 lakhs school teachers, 29 lakhs are women.

R Govinda, vice-chancellor, National University of Education Planning and Administration (NUEPA), said, "This change has been induced because of government policy. Out of every two teachers a school recruits today, one has to be a woman."(7)

Psychiatrist Harish Shetty, who doubles up as counselor for several city schools, said post-industrialization research has proved that the male role model was increasingly missing from the lives of growing boys. What this means is that at home, the father is away at work most of the time, and in school, the student rarely has a male teacher to look up to. (8)

\section{Gender Roles of Female Teachers: At Family}

A woman's primary work is running or managing her family's home, caring for her children; buying, cooking, and storing food for the family; buying goods that the family needs for everyday life; housekeeping, cleaning, and maintaining the home, and taking care of clothes for the family.

Besides that, taking care of older people, receiving guests, and performing religious activities are also her traditional gender roles.

The traditional family responsibilities that women hold in families and their motherhood makes it easy for them to relate to students in school. This is undoubtedly a significant advantage that facilitates teaching.

\section{At the workplace}

It is now common to hear that in private schools a teacher has been 'promoted' to 'Team Leader' or 'Academic Head', 'Head - Training and Development', and other such designations. It is definitely sounding like the corporate world. Well, they certainly resonate with the corporate lingo. Teachers say that in her school, teachers are not compensated for these additional roles they take on. Instead, politics and power games have become the order of the day.

Teachers are the central part of a school system along with students. For the educational programs to be efficient, the quality of teachers is highly essential.

Teachers, who play a vital role in shaping the society, actually spend a mere $19.1 \%$ of their working hours in imparting knowledge. In the remaining time, they 
RJPSS Sept. 2020 Vol. XLV No.2, ISSN: (P)0258-1701 (e)2454-3403 Impact Factor: 7.717

https://doi.org/10.31995/rjpss.2020.v45i01.023

do election duty, carrying out surveys, pulse polio campaigns, and maintaining midday meal registers if they are the government. Government school teachers say their responsibilities, in addition to teaching, are spread throughout the year, and the report translates that claim into compelling numbers. (9)https:// www.educationworld.in/teachers-spend-only-19-1-per-cent-time-teaching-saysnuepa-report/

\section{Review of literature:}

For the reason of logical analysis and assessment of the change of gender roles, the studies by a number of researchers have been re-examined and in their studies, highlighted that female school teachers are playing multiple gender roles. These studies also show a strong correlation between work-life balance and working females, if amenities are made available by the organization. (10)

h t t p s : / / w w w.res e a r c h gate.net/publication/ 329969713 Job_Stress among Female Teachers of Rural_Primary School

Overloadedness and role-conflict are the main factors of job stress among female primary school teachers. The primary school female teachers, who have charge of the school, have significantly higher job stress than the primary school female teachers who do not have the charge of the school. So effort should be made not to allow non-teaching work to these primary school teachers to reduce their stress. (11)

https://www.ncbi.nlm.nih.gov/pmc/articles/PMC6058447/\#sec1-3title

Kandel et al. in their study on the impact of multiple roles on the mental health of working women reported that the balance between rewards and concerns in the wife; mother and paid worker roles show a stronger negative relationship with depression among women. (12)

Verbrugge (1983) also found that employment, marriage, and parenthood are associated with good physical and mental health in women. According to him, employed married mothers tend to have the best health profile and, of the three roles, employment has the strongest effect on health. He concluded that multiple roles have no special effect on health either positively or negatively. People with both jobs and family roles enjoy the health benefits of each role and incur no special health disadvantage or benefit for being so busy in their different roles (13)

A study on "Work-Life Balance of Married Female Teachers in Government and Private Schools of Raipur, Chhattisgarh" by Mrs. Pratibha Barik, 2017 has explored that both in government and private schools female married teachers are unhappy with work-life balance. But still, they are struggling hard to somehow manage between work-life. (14) 
Changing Gender Roles: In Context of Female School Teachers of Ranchi

Mrs. Omi Singh, Dr. Vinita Singh

\section{Methodology:}

This study includes exploratory research on the concerned areas. Exploratory in the sense, that it tried to explain how different gender roles of female school teachers are. The present study is interested in finding answers to the questions about gender roles, work-life balance, workload, and stress.

\section{Data Collection}

The researcher also used an interview technique for the collection of data. The researcher followed a semi-structured interview technique because it was less structured than a questionnaire-based interview and it also allowed respondents to talk at length. We have tried to use the latest concepts in management to highlight the situation in the context of such a problem and tried to suggest some of them for correcting the situation.

\section{Conclusions and recommendation:}

The study has explored that both in government and private schools female married teachers are unhappy with work-life balance. But still, they are struggling hard to somehow manage between work-life. In this adverse situation, they have learned to manage their time efficiently. Further, the research revealed that the female workforce decides their priorities and accordingly they manage their time at home and school. They try to get household support from servants, parents/in-laws, children, and even from their husbands. Apart from this the choice to work at their nearby school to save their traveling time. Female workforce is good time managers, but still, the biggest responsibility in front of a married woman is to take care of her rearing kid and household chores. So an institution should take an initiative to execute work-life balance policies and practices like flexi-hours, childcare centers, restrooms to take a nap, if possible can provide accommodation to them as it will save their traveling time, etc.

\section{Reference}

1. https://www.oxfordlearnersdictionaries.com/definition/american_english/gender

2. https://www.who.int/reproductivehealth/topics/sexual_health/sh_definitions/e 12. Nov2020 $6.45 \mathrm{pm}$

3. https://www.who.int/health-topics/gender

4. https://kinseyinstitute.org/about/profiles/john-money.php

5. https://www.who.int/health-topics/gender

6. https://unesdoc.unesco.org/ark:/48223/pf0000370966

7. http://archive.mu.ac.in/DETAILS\%20R\%20GOVINDA\%20POSTER.pdf 
RJPSS Sept. 2020 Vol. XLV No.2, ISSN: (P)0258-1701 (e)2454-3403 Impact Factor: 7.717

https://doi.org/10.31995/rjpss.2020.v45i01.023

8. http://www.menteach.org/news/

teachers_day_45_of_teachers_in_indian_school

9. https://www.educationworld.in/teachers-spend-only-19-1-per-cent-timeteaching-says-nuepa-report/

10. https://www.researchgate.net/publication/

329969713_Job_Stress_among_Female_Teachers_of_Rural_Primary_School

11. https://www.ncbi.nlm.nih.gov/pmc/articles/PMC6058447/\#sec1-3title

12. https://www.ncbi.nlm.nih.gov/pmc/articles/PMC6058447/

13. http://www.iosrjournals.org/iosr-jhss/papers/Vol.\%2022\%20Issue11/Version-4/ F2211043846.pdf

14. http://ijrmbs.com/vol4issue4/sahdeep.pdfISSN : 2348-893X (Print). Work-

Life Balance among Female School Teachers: An Empirical Study of Chittorgarh. Sandeep Chhatrapati. 